\title{
Health dispossessions and the moralization of disease: the case of diarrhea in the Mekong Delta, Vietnam
}

\author{
Panagiota Kotsila ${ }^{1}$ \\ Universitat Autònoma de Barcelona, Catalonia, Spain
}

\begin{abstract}
Despite the swift development of Vietnam's water supply and sanitation (wat/san) sector, over the last ten years there have been 1.5 million annual documented cases of diarrhea. Western perspectives blame insufficient medical or economic advancement for failing to prevent diarrhea and its treatment, failing to grasp how disease is shaped in the cultural, moral and political domain. This article examines the nature and function of public health policy and discourse against the spread of the disease in Can Tho City, Mekong Delta. Some 94 qualitative interviews were conducted with government representatives, medical staff and water experts, and a survey of 131 households in urban and rural areas. Focusing only on improving the construction of wat/san 'hardware' does not improve 'cultural software', and ignores the needs of vulnerable minorities, compromising the control of diarrhea. I also show how state discourse follows neoliberal approaches in individualizing health responsibilities, and moralizing disease. Local (mis)perceptions and risky behaviors emerge as the result of structural constraints that include poverty, a lack of access to useful health information, and the cultivation of stigma around diarrhea. These types of health dispossessions serve a political purpose, where the state escapes responsibility for public health failures, and thus enhancing its efforts to maintain legitimacy as a good implementer and a 'caring head.'
\end{abstract}

Keywords: Vietnam, public health, health individualization, moralization of disease, blame discourse, diarrhea.

\section{Résumé}

Malgré le développement rapide du secteur de l'approvisionnement en eau et de l'assainissement (wat / san) au Vietnam, il y a eu au cours des dix dernières années 1,5 million de cas annuels de diarrhée. Les perspectives occidentales accusent l'insuffisance de progrès médicaux ou économiques pour ne pas prévenir la diarrhée et son traitement, ne comprenant pas comment la maladie est façonnée dans le domaine culturel, moral et politique. Cet article examine la nature et la fonction de la politique de santé publique et le discours contre la propagation de la maladie dans la ville de Can Tho, dans le delta du Mékong. Quelque 94 entrevues qualitatives ont été menées auprès de représentants du gouvernement, du personnel médical et des experts en eau, et une enquête auprès de 131 ménages vivant en milieu urbain et rural. Se concentrer uniquement sur l'amélioration de la construction du «matériel» wat / san n'améliore pas les «logiciels culturels» et ignore les besoins des minorités vulnérables, compromettant ainsi le contrôle de la diarrhée. Je montre aussi comment le discours d'Etat suit les approches néolibérales en individualisant les responsabilités en matière de santé et en moralisant les maladies. Les perceptions locales et les comportements à risque sont le résultat de contraintes structurelles qui incluent la pauvreté, le manque d'accès à des informations utiles sur la santé et la propagation de la stigmatisation autour de la diarrhée. Ces types de dépossession de la santé servent un but politique, où l'État échappe à la responsabilité pour les échecs de santé publique, et ainsi renforcer ses efforts pour maintenir la légitimité en tant que bon exécutant et une «tête de soins».

Mots-clés: Vietnam, santé publique, individualisation de la santé, moralisation de la maladie, discours du blâme, diarrhée.

\footnotetext{
${ }^{1}$ Dr. Panagiota Kotsila, Post-Doctoral Fellow, Institute for Environmental Science and Technology (ICTA), Universitat Autònoma de Barcelona, European Network of Political Ecology (ENTITLE). Address: Edifici Z, Carrer de les columnes, E- 08193 Bellaterra, Spain. Email: panagiota.kotsila "at" gmail.com. This work received funding from the European Union's Seventh Framework Programme for research, technological development and demonstration (Marie Curie Actions) under grant agreement no 289374 (ENTITLE), and the German Ministry of Education and Research (BMBF) through the WISDOM project (2011- 2014). I am grateful to Prof. Solvay Gerke and to Dr. V.S. Saravanan for their support, as well as to my colleagues from ENTITLE in ICTA and two referees for commenting on previous drafts of this article. This is the fifth article in Creighton Connolly, Panagiota Kotsila, and Giacomo D'Alisa (eds.) 2017. "Tracing narratives and perceptions in the political ecology of health and disease", Special Section of the Journal of Political Ecology 24: 1-124.
} 


\section{Resumen}

A pesar del rápido desarrollo de su sector de abastecimiento de agua y saneamiento en las últimas décadas, Vietnam ha tenido 1,5 millones de casos documentados anuales de diarrea en los últimos 10 años. Perspectivas occidentales en todo el mundo atribuyen las limitaciones en la prevención y el tratamiento de la diarrea en una insuficiencia del avance médico o económico, con lo cual no llegan a comprender cómo la enfermedad se forma en el ámbito cultural, moral y político. En este artículo se examina la naturaleza y la función de la política y del discurso alrededor de la salud pública contra la propagación de diarrea en Can Tho City, en el Delta del Mekong. Los resultados provienen de 94 entrevistas cualitativas con representantes del gobierno, personal médico y expertos en agua, y una encuesta de 131 hogares en zonas urbanas y rurales. Se demuestra, en primer lugar, por qué de-priorizar "software" y otros aspectos preventivos, y enfocarse sólo en la construcción de instalaciones "hardware" en agua y saneamiento, supone hacer caso omiso de las necesidades de minorías vulnerables y compromete el éxito en el control de la enfermedad. En segundo lugar, se muestra cómo el discurso del estado sigue tendencias neoliberales, individualizando responsabilidades de salud y moralizando la enfermedad. (Mal)percepciones y prácticas de riesgo surgen en nivel local como resultados de limitaciones estructurales que incluyen la pobreza, la falta de acceso a la información de salud útil, y el cultivo de estigma en torno a la diarrea. Estos tipos de desposesión de salud sirven a un propósito político, donde el estado se escapa su responsabilidad de los fracasos en la salud pública, mejorando así sus esfuerzos para mantener su legitimidad como un buen ejecutor y una "cabeza que cuida".

Palabras claves: Vietnam; salud pública; individualización de salud; moralización de la enfermedad; discurso de la culpabilización; diarrea.

\section{Diarrhea prevention beyond 'scientized' and 'hardware' solutions}

A tendency over the last century and a half has been to 'scientize' complex phenomena rather than democratize decision-making processes about them. As a result, such phenomena have received apolitical explanations and responses (P. Brown and Zavestoski 2004; Kinchy 2010). This holds true for public health problems, sometimes claimed to be effectively managed because they are non-political (Goldberg 2012). Public health has been turning into a 'scientized' domain managed by experts and technocrats, ignoring the structural constraints and environmental injustices that create health-impairing conditions. Disease is thereby disconnected from its biophysical and cultural environment and, as a consequence, stripped of its political dimensions.

Based on western knowledge (biomedical, technological and industrial), health policy priorities have been monopolized by efforts to satisfy global indicators, commonly established by international development agencies (Molle and Mollinga 2003; Schmidt 2014). A public health discourse can place material advancement and modernization as the easiest response to problems identified through a "top-down ethnocentric and technocratic" approach (Escobar 1997: 89). Central states, institutions and the market have captured power by aligning their interests, claiming control over "the well-being of all." In this context, disease has often acted as the pretext for establishing imperatives along the lines of growth and technological development (Ayo 2012; Hunt 2003).

Despite the great health benefits that water and sanitation initiatives (henceforth, wat/san) have contributed, particularly in the fight against diarrheal disease (Cairncross et al. 2013), this sector is dominated by top-down priorities and the achievement of global goals that do not necessarily address local realities and needs. It has been shown that the often advocated 'hardware' components of wat/san alone (e.g. pipes and sanitation) are not sufficient to address health risks. Cairncross et al. (2010), for example, posit that for diarrheal disease prevention programs to be successful, better access to adequate water and hygienic sanitation facilities needs to be combined with 'software' measures, such as the promotion of hand-washing with soap. In general, the everyday practices and lay perceptions around hygiene have proven crucial in shaping disease outcomes, even when improved water sources and sanitation facilities are accessible (V. Curtis, Cairncross and Yonli 2000; Heller, Colosimo, and Antunes 2003; Jensen et al. 2002; Mintz, Bartram, Lochery and Wegelin 2001).

'Scientized' approaches to public health issues frequently interpret disease-related challenges simplistically, as the result of inefficient public health programs, incompetent health workers, or the public's 
cognizance or behavioral incapacities. All of the above, but particularly the latter, are often linked to claims around 'local culture', where culture is falsely seen as an opposite to, or an obstacle for science. This article begins with the premise that such approaches are apolitical and must be challenged. It shows how they fail to grasp the complexity and essence of disease as the socio-political phenomenon that it is, and they disallow potentially useful answers to health problems, including the persistence of diarrhea.

Building on critical literature on what shapes and defines health risks from the fields of cultural theory, medical anthropology and political ecology (Ayo 2012; Douglas 1970; Guttman and Salmon 2004; Lupton 1993; Nash 2006; Singer 2009, et al.), this article calls for a deeper and more critical analysis of what shapes human health. Focusing on the communication of health messages and discourse around disease, I analyze the public health approach to fighting diarrhea in Vietnam, through a case study of Can Tho City in the Mekong Delta. Applying an "epidemiology of health communication" (Nichter 1996: 165), I draw specific attention to the underlying claims that guide and penetrate health messages, questioning the reasons behind their generation and their impacts on common perceptions, behaviors and practices related to diarrheal disease.

\section{Health dispossessions: an analytical framework}

Health dispossession is experienced through the deprivation of access to health-facilitating conditions or resources. Neoliberal ideology has shaped unequal health vulnerabilities, especially when states become more preoccupied with assisting with, or being part of, an endless pursuit for capital circulation, than safeguarding citizens' universal right to health (Ayo 2012). Lupton (1993) aptly notes how bottom-up calls for health justice are extremely difficult to appreciate when global capital and powerful politicians "in a position both to define health risks and to identify their solutions" simply do not want to listen (Ibid. 1993:432).

Political ecologists have often highlighted the injustice and inequality that characterizes how material processes (of extraction, production, exchange or disposal) impair human health (Bullard and Lewis 1996; Couacaud 2014; Quesada, Hart, and Bourgois 2011; Richmond et al. 2005; Singer et al. 1992). They have emphasized how marginalized, excluded, discriminated against, or otherwise oppressed populations have also been the most vulnerable to health risks. Critical medical anthropologists and cultural theorists see the meanings and messages around disease as important factors in inequality and injustice. They also claim that locally evidenced (mis)conceptions or (mis)behaviors increasing the risk of disease require an analysis of the structural and cultural realities of those whose health is at stake (Aunger et al. 2010; Joshi, Fawcett, and Mannan 2011; Nichter and Nichter 1996; Panter-Brick et al. 2006; Smith et al. 1993).

Studies that combine these two parallel lines of inquiry are necessary for understanding the dynamics of human health and the spread of disease, but they are rare. This article discerns health dispossessions as taking place simultaneously in physical/material and knowledge/cultural terms. I therefore propose an analytical framework that looks at the triangle of individualization, moralization and stigmatization of disease. I see these processes as distinct but interrelated forms of health dispossessions that are reflecting neoliberal tendencies in public health, and which act to legitimize certain ideologies and practices.

\section{Individualizing, stigmatizing and moralizing disease}

Disease avoidance is often presented as a personal duty, accompanied by the use of "healthier" products (Guttman and Salmon 2004; Tesh 1988). By placing the focus on the "enterprising individual", state responsibilities can thus be abdicated (Ayo 2012: 103). In this neoliberal vein, disease no longer represents policy weaknesses, but the weak individual judgments. This serves to conceal practical constraints and power imbalances that define the range of choice that individuals, local communities and health professionals have, in terms of health behaviors, as seen for instance in the cases of alcohol consumption, daily exercise, treatment-seeking strategies, or (non)holistic approaches to disease prevention (Feierman et al. 2010; Singer et al. 1992). Although individualizing health responsibilities has been seen to exacerbate health inequities (Langford and Panter-Brick 2013), such discourse is a tactic to justify the de-prioritization of social welfare policy. 
As a fundamental and strengthening element of the individualization discourse, unhealthy behaviors are repeatedly assigned to specific "cultures" (local, religious, ethnic, class- or region- based). This often leads to the stigmatization of people in disease-vulnerable positions, which in turn can promote social exclusion and have double negative effects on health: further amplifying biophysical conditions that favor disease and disallowing the necessary social cohesion to prevent or overcome it (Geddes 2000; Wallerstein 2006). Feelings of social marginalization have been proven to cause negative reactions towards state promotion campaigns in the sanitation sector, as seen in the case of Vietnam (Rheinländer et al. 2010). Using reified notions of culture as valid claims around health and disease is, thus, one more form of health dispossession that works in concert with the neoliberal axiom of acting on one's own "free choices" (T. Brown and Duncan 2002).

Foucault's concept of governmentality (Foucault 1991) explains how health promotion can shape people's decisions, "inciting the desire [...] to follow the imperatives set out by health promoting agencies, and thus, take on the responsibility of changing their own behaviors accordingly" (Ayo 2012). Governmentality can refer to "the relation between self and self, private interpersonal relations involving some form of control or guidance, relations within social institutions and communities" or "relations concerned with the exercise of political sovereignty" (Foucault et al. 1991: 2). In other words, it is "a form of activity aiming to shape, guide or affect the conduct of some person or persons" (Ibid. 1991). A particular characteristic of this "(self)regulatory regime", which actively shapes individual behaviors in the context of health, is the focus on disease risk factors and not on disease itself (Brown and Duncan 2002 citing Lupton 1998). This focus shifts the epidemiological and the moral gaze a step back: from avoiding harm, people are prompted to avoid what can cause harm - according to public health experts (Rozin 1999). They are led to regulate their behaviors, expecting others to do so, or demanding central control over such aspects for the sake of public health.

Hunt (2003: 171) recognizes the "interaction between the practices of governing others and governing the self" interferes with people's conduct and deepens the moralization of experiences and actions. Claims on public health can this way appear as utilitarian and benign when functioning through proxies of "harm" or "risk", neutralizing moral discourse that can be deeply discriminating and stigmatizing (Hunt 2003; Lupton 2014). Moralizing disease and casting aspersions on already vulnerable social groups has in fact been a historical tendency (Rozin 1999). Yet the (un)intended adverse effects of communication messages have not been critically analyzed sufficiently (Guttman and Salmon 2004), especially in the modern neoliberal context. In one exception, when Lupton (1993) re-visits Purity and Danger (Douglas 1970), she notices how Douglas' theory needs to be reversed in order to understand how individualizing health responsibilities connects to the moralization of disease in the modern context. She notes how it is not the sinners who are punished with their risky positioning but, conversely, it is those who allow themselves to be "at risk" who are considered to be the "sinners" (Lupton 1993: 429).

A general lack of critical ethical discussions in public health is particular noteworthy in Vietnam. Vietnamese authorities prefer survey-based quantitative studies, discounting qualitative social studies (Waibel and Ehlert 2012). There is an ongoing debate about how to discern the reverberations of global capitalism in a nation-state that still claims to be socialist, and whether neoliberalism is a useful concept for understanding market-state-society interactions in the country (Gainsborough 2010; Schwenkel and Leshkowich 2012). Anglo-American neoliberal tendencies have deprioritizing social welfare since the 1970s, favoring free market activity and the ethics that accompany it. These tendencies are also observable in posttransitional (Springer 2010) and (post)socialist contexts (Bohle and Greskovits 2007). They produce a "cacophony of socialist and neoliberal governmentality" (Bui 2015), strongly felt in the field of health (Janes et al. 2006).

Lincoln (2014) has shown how "healthism" and the individualization of health responsibilities played out during a 2007/2009 cholera epidemic (severe form of diarrhea) in Northern Vietnam, illustrating how "officials, media, and citizens not only identified scapegoats and proposed solutions, but also endorsed particular visions of moral conduct, social order, and public health" (Ibid. 2014). This article explores forms of health dispossessions in Vietnam, taking the case of diarrheal disease. It explores how stripping disease of its political dimensions plays out in various spheres, from policy formulation and implementation to public 
discourse, exploring how this contributes to health communication's power "to legitimize ideologies and social practices" in Vietnam (Ibid. 1993). My study is informed by critical scholarship on public health and risk-related governmentality, to enrich the conversation about how such issues are expressed and experienced.

\section{Methodology and case study background}

Research was conducted over ten months in 2011 in the Mekong Delta, Vietnam (Figure 1). The methodology included semi-structured and in-depth interviews, as well as a household survey. Observation of participants and documentation in the form of field-notes took place throughout my stay in Can Tho City and during visits to Ho Chi Minh City and Hanoi. Secondary sources included legal documents, governmental reports, online media, newspapers and state-produced educational material, analyzed qualitatively and quantitatively. This mixed-methods collection and analysis accounted for the context, the circumstances and possible motivations in the generation of the data, where "data and theoretical ideas were played off against one another in a developmental and creative process" (Blaikie 2009: 156).

Local permits were obtained from the relevant Vietnamese authorities and informed (verbal) consent to participate was obtained from all participants. ${ }^{2}$ Being able to do research in Vietnam required a preexisting contact with state institutions, which was guaranteed through my institutional and project affiliation (see also Ehlert 2011; Kotsila 2014). I had to provide a research plan listing the desired offices and organizations to be visited, their purpose and topics of discussion, and exact dates and times. The offices assigned a respondent, whose name or title would not be made known beforehand.

In the first phase, interviews were with representatives from district, provincial and national level organizations (Table 1). This round of consultations led to the selection of Cai Rang and Phong Dien as case study locations, representing the urban and rural character of Can Tho. During a second phase, district interviews on the implementation of policy were conducted, to understand the context and function of locallevel governance. The third phase consisted of a household survey in two neighborhoods of Le Binh ward (the most urbanized part of Cai Rang), and in the Giai Xuan and Truong Long communes (rural parts of Phong Dien) (Figure 2).

In-depth interviewing of local residents would have been preferable, but strict official requirements did not allow for autonomous or spontaneous research. The survey became a 'Trojan horse' to gain access to rural and urban households. It produced quantitative data, but also allowed some space and time for observation and discussion with local citizens. I only sampled $2 \%$ of households in each district, but targeted the surveys (in collaboration with local authorities) to explore factors known to affect diarrheal disease (poverty, access to surface water, access to tap water). The questionnaire was revised from Köster (2008) and SPSS software was used for analysis. Through the daily interaction with community members and representatives from local state administration, the variation in lifeworlds became legible. Adaptability in conducting research was necessary to balance official restrictions and a desire to explore issues more deeply (Waibel and Ehlert 2012).

Respecting customs and procedures, I conducted nine in-depth interviews with key informants from the case study districts. Finally, thirty offices were visited or revisited for interviews, in order to present state representatives with the household survey results, confront them with contradictory data, and triangulate findings.

\footnotetext{
${ }^{2}$ Institutional ethics review was not required by my academic institutions in Europe or Vietnam.
} 


\begin{tabular}{|c|c|c|c|c|c|}
\hline \multirow{2}{*}{ Research phase } & \multicolumn{5}{|c|}{ Number of interviews } \\
\hline & Commune & District & Province & Ministry & TOTAL \\
\hline $\begin{array}{l}\text { 1: Contextualization (semi-structured } \\
\text { interviews) } \\
\text { Hospitals, preventive health centers, offices of } \\
\text { health, Department of Natural Resources and the } \\
\text { Environment, Centre for Rural Water Supply and } \\
\text { Sanitation, Institute of Public Health and Hygiene, } \\
\text { medical universities, Institute for Socio-economic } \\
\text { Development, WHO, UNICEF. }\end{array}$ & - & 13 & 10 & 4 & 27 \\
\hline $\begin{array}{l}\text { 2: Selected districts (semi-structured } \\
\text { interviews) } \\
\text { Women's Union, Farmer's Union, Youth Union, } \\
\text { Red Cross offices, health offices, health clinics, } \\
\text { Department of Education, Department of } \\
\text { Economic and Social Policy, schools and } \\
\text { kindergartens. }\end{array}$ & 3 & 18 & - & - & 21 \\
\hline 3: Household survey ${ }^{3}$ & 131 & - & - & - & 131 \\
\hline 4: Selected households (in-depth interviews) & 9 & - & - & - & 9 \\
\hline $\begin{array}{l}\text { 5: Targeted visits for triangulation (semi- } \\
\text { structured interviews) } \\
\text { Offices of health, preventive health policy and } \\
\text { water supply and sanitation. }\end{array}$ & 8 & 10 & 6 & 6 & 30 \\
\hline TOTAL & 151 & 41 & 16 & 10 & 218 \\
\hline
\end{tabular}

Table 1: Number of interviews conducted by research phase and by administrative level.

\footnotetext{
${ }^{3}$ Sample characteristics:

- $\quad$ 25/131 households were officially classified as poor or nearly poor, and the rest were of average income.

- $\quad$ 83/131 women respondents.

- $\quad 45 \%$ of the respondents were $36-56$ years old, $43 \%$ over-56.

- $\quad$ 17/131 respondents were illiterate, 47/131 had elementary education, 27/131 had attended junior high school, 38/131 secondary high school and 1/131 higher education.
} 


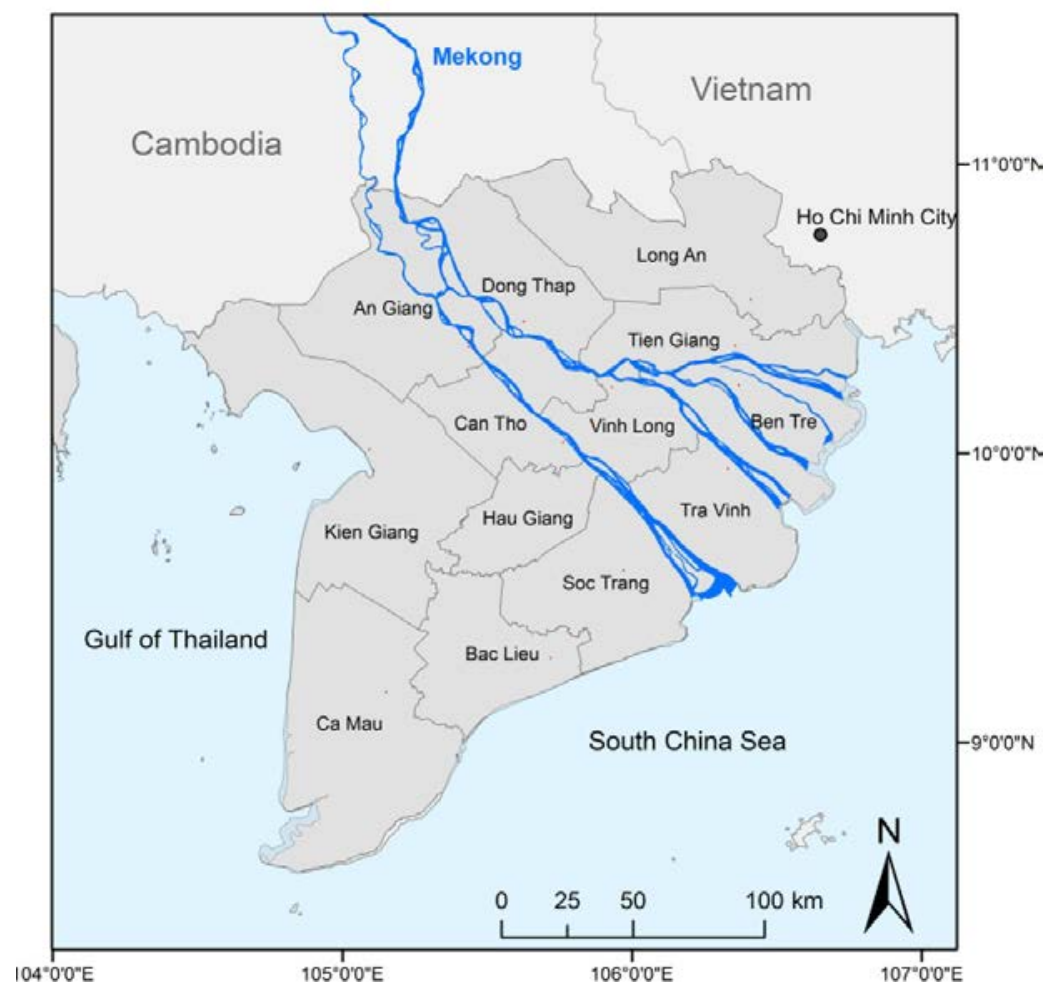

Figure 1: Map of the Mekong Delta, Vietnam. Source: Kuenzer et al. (2013).

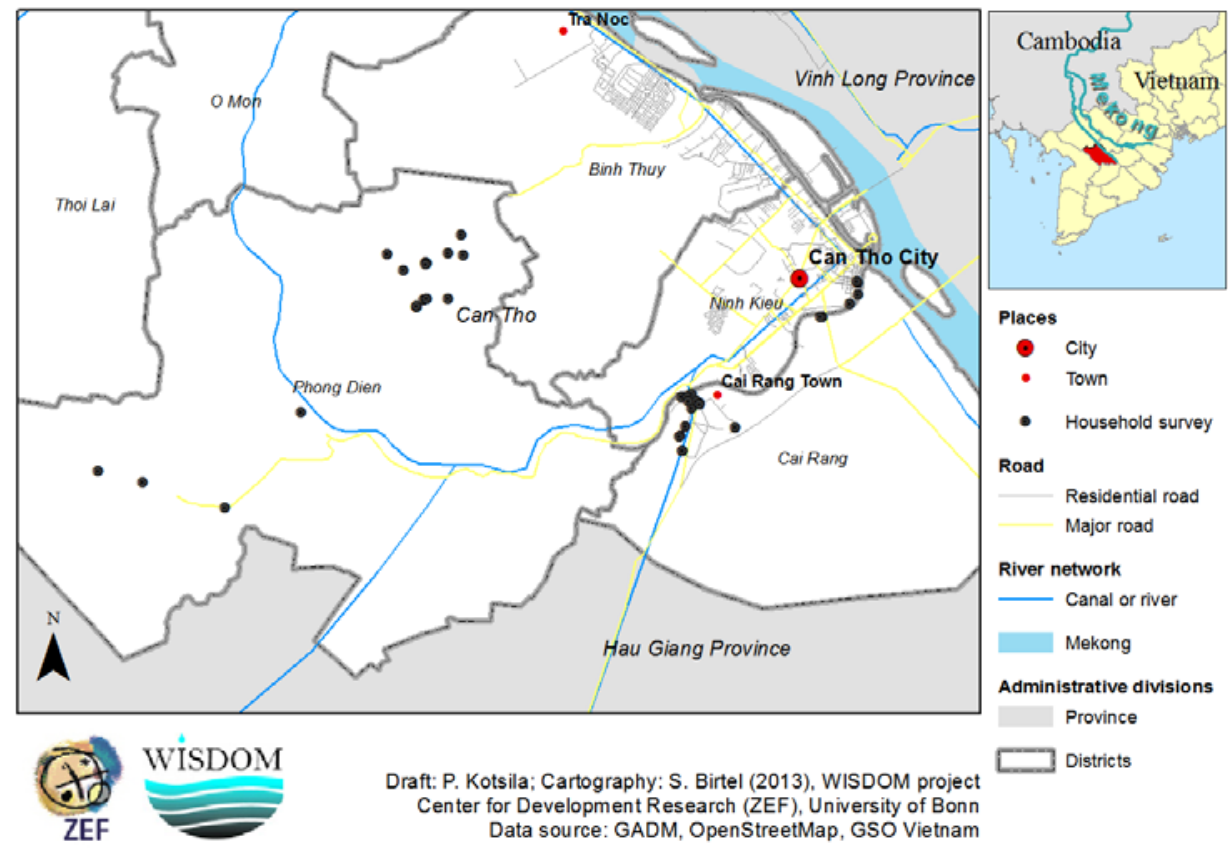

Figure 2: Map of Can Tho City and indicated household survey locations. Source: listed. 


\section{Case study background}

Vietnam has transitioned from being one of the world's poorest countries in the 1990s (World Bank 2013) to having high levels of growth and macroeconomic stability (GSO 2013; Thanh and Duong 2009). ${ }^{4}$ International development reports show mortality rates among children under five to have decreased dramatically from 51 to 23 (per 1,000 births) for the years 1990-2010 (UNICEF (Viet Nam) 2012). The incidence of diarrhea has also fallen, from $6^{\text {th }}$ to $27^{\text {th }}$ in the ranking of 'causes of years of life lost due to premature mortality' over the same period (Institute of Health Metrics and Evaluation [IHME] 2010). At the same time, access to improved water supply and sanitation (wat/san) has increased on average (Figure 3 and 4).

\begin{tabular}{|c|c|c|c|c|c|c|}
\hline Surface water & \multirow{5}{*}{\multicolumn{2}{|c|}{ 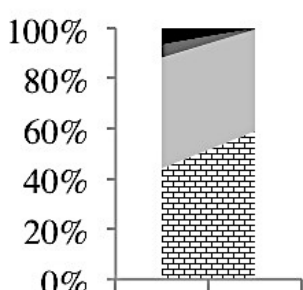 }} & \multirow{6}{*}{$\begin{array}{r}100 \% \\
80 \% \\
60 \% \\
40 \% \\
20 \% \\
0 \%\end{array}$} & & \multirow{5}{*}{\multicolumn{2}{|c|}{$\left.\begin{array}{r}100 \% \\
80 \% \\
60 \% \\
40 \% \\
20 \%\end{array}\right]$}} \\
\hline & & & & & & \\
\hline Other unimproved & & & & & & \\
\hline & & & & & & \\
\hline Other improved sources & & & & & & \\
\hline $\begin{array}{l}\text { Piped onto premises } \\
\text { (central provision) }\end{array}$ & & $\begin{array}{c}1990 \mid 2010 \\
\text { urban }(\%)\end{array}$ & & \begin{tabular}{c|c}
1990 & 2010 \\
rural $(\%)$
\end{tabular} & $0 \%$ & \begin{tabular}{c|c}
1990 & 2010 \\
total $(\%)$
\end{tabular} \\
\hline
\end{tabular}

Figure 3: Improved water supply access in Vietnam between 1990 and 2010. Adopted from Kotsila (2014). Data based on the JMP (2012a).

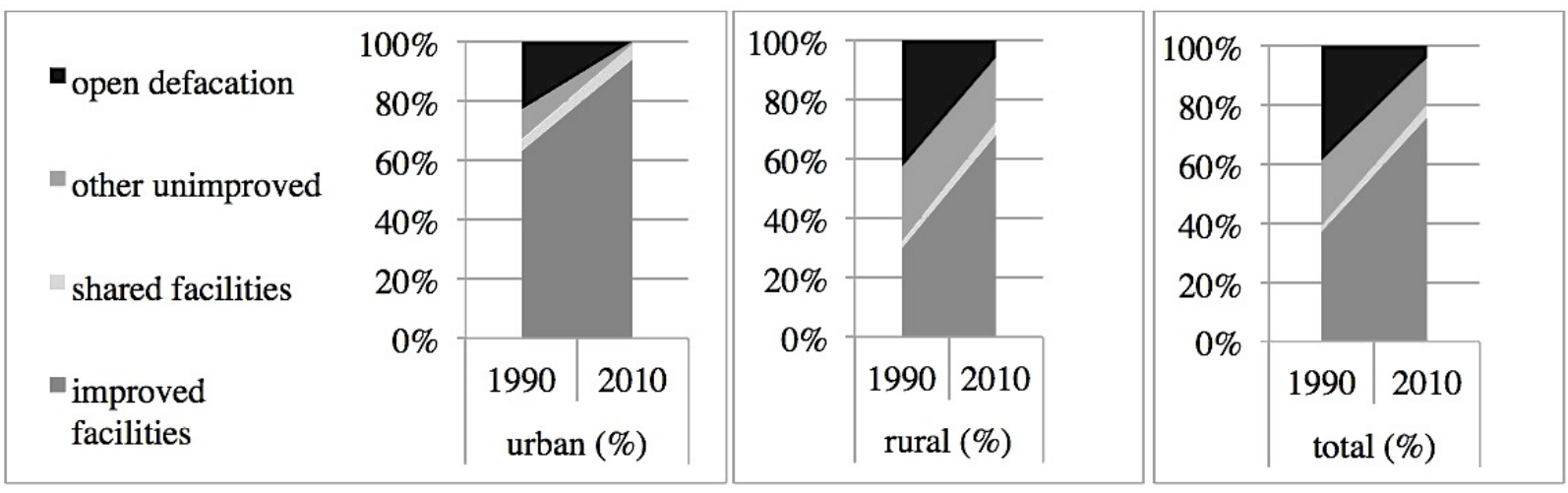

Figure 4: Improved sanitation access in Vietnam between 1990 and 2010. Adopted from Kotsila (2014). Data based on JMP (2012b).

Diarrhea-control programs in Vietnam began in the 1980s and for more than a decade they helped to reduce the disease (WHO 1987). Tackling diarrhea has been less successful over the last twenty years (Lincoln 2014; Trach et al. 1997; Van Man et al. 2005). Diarrheal disease is difficult to document, as most cases get treated at home or by private practitioners, and thus do not enter official health records (Kotsila

\footnotetext{
${ }^{4}$ Today Vietnam is considered to be a 'lower middle income' country by the World Bank.
} 
2012, 2014). It appears they are responsible for $10 \%$ of mortality under 5 years of age (World Health Organization [WHO] 2012). Although mortality has fallen since 1990, morbidity levels are still high with an average of over 1.5 million documented annual cases from 2005 to 2011 (MoH 2012). Moreover, those living in poverty are still the most exposed and vulnerable to diarrhea, both globally and in Vietnam (UNICEF 2012). Local access to wat/san facilities is still worse in rural areas (Figures 3 and 4), and varies by income level and ethnic origin (Cairncross et al. 2013; Rheinländer et al. 2010)

Previous studies on the Mekong Delta have indicated that the links between water, sanitation and hygiene are poorly understood, increasing people's exposure to diarrheal disease (Herbst et al. 2009; Reis and Mollinga 2012). Public health information and education around the issue is poor or insufficient, and the diarrhea challenge is still significant. Questions exist about why there is poor prevention and control.

\section{Results}

\section{Health messages for diarrhea prevention: de-prioritization in a system of hierarchy}

In the 1970s, the Vietnamese government was mobilizing and training many workers on full salaries to spread public health messages, while social behavior compliant to public health principles already constituted an official obligation for citizens (Bloom 1998). As part of the political and economic Doi Moi policy changes in the 1980s, the health sector was decentralized and private medical services bloomed in Vietnam. These shifts affected the quality and the accessibility of public health care (for a detailed account of the deterioration of the local health system see Forsberg 2011, Kotsila 2012, Priwitzer 2012, and Witter 1996). This has affected health promotion and education activities at the local level. The Ministry of Health recognized these as crucial for disease prevention (MoH 2007: 96, 2010).

In the legal texts, 'information, education and communication' activities (IEC) appear as the key for preventing infectious diseases (MoH 2007, 2010). Emanating from international think tank guidelines (WHO 2001), the development of this triptych concept assumes external expertise can tackle a well-defined health problem and the public can be made aware of how to prevent it. IEC is an inherently top-down approach, often adopted as a blueprint for achieving health goals. The head of the Can Tho Health Education and Communication Centre described how the conceptualization and the implementation of IEC in Vietnam is embedded in the hierarchical pyramid of the Party-state (personal interview 14/12/2011, Figure 5). Interviews with the directors of five district-level preventive health centers (PHC) in Can Tho, confirmed this rigidly structured flow of information within the state's bureaucracy. Even so, the WHO claimed the objective of IEC is to "empower people vis-à-vis their health actions, and garner social and political support for those actions" while concentrating on the opinions, worldviews and feedback of the target audience (WHO 2001).

Unlike malaria or HIV, the control of diarrhea does not constitute a clear priority in today's Vietnam, but it is addressed peripherally under the water supply and sanitation program for rural areas (GoV 2006, 2007). The health information component only receives a minor part of the overall budget (9\%) (GoV 2006). Health messages around diarrhea are supposed to trickle down to the localities through two types of activities: 'training-of-trainers' events, and door-to-door visits by health communicators. The first are group gatherings, where expert representatives from the city's Preventive Health Centre (PHC) are sent to the communes, in order to "update local trainers on preventive health priorities and practices" (see also Figure 5). There are no more than forty such events taking place annually in Can Tho (a city of about 1.2 million people), and no more than fifty people are allowed to participate per event:

We cannot afford for more. The refreshments offered cost money. The number of the people is pre-decided, or else we wouldn't be able to afford it. Those who come are cadres from offices or somehow hold a position in their localities. (Top official in PHC of Can Tho, semistructured interview) 


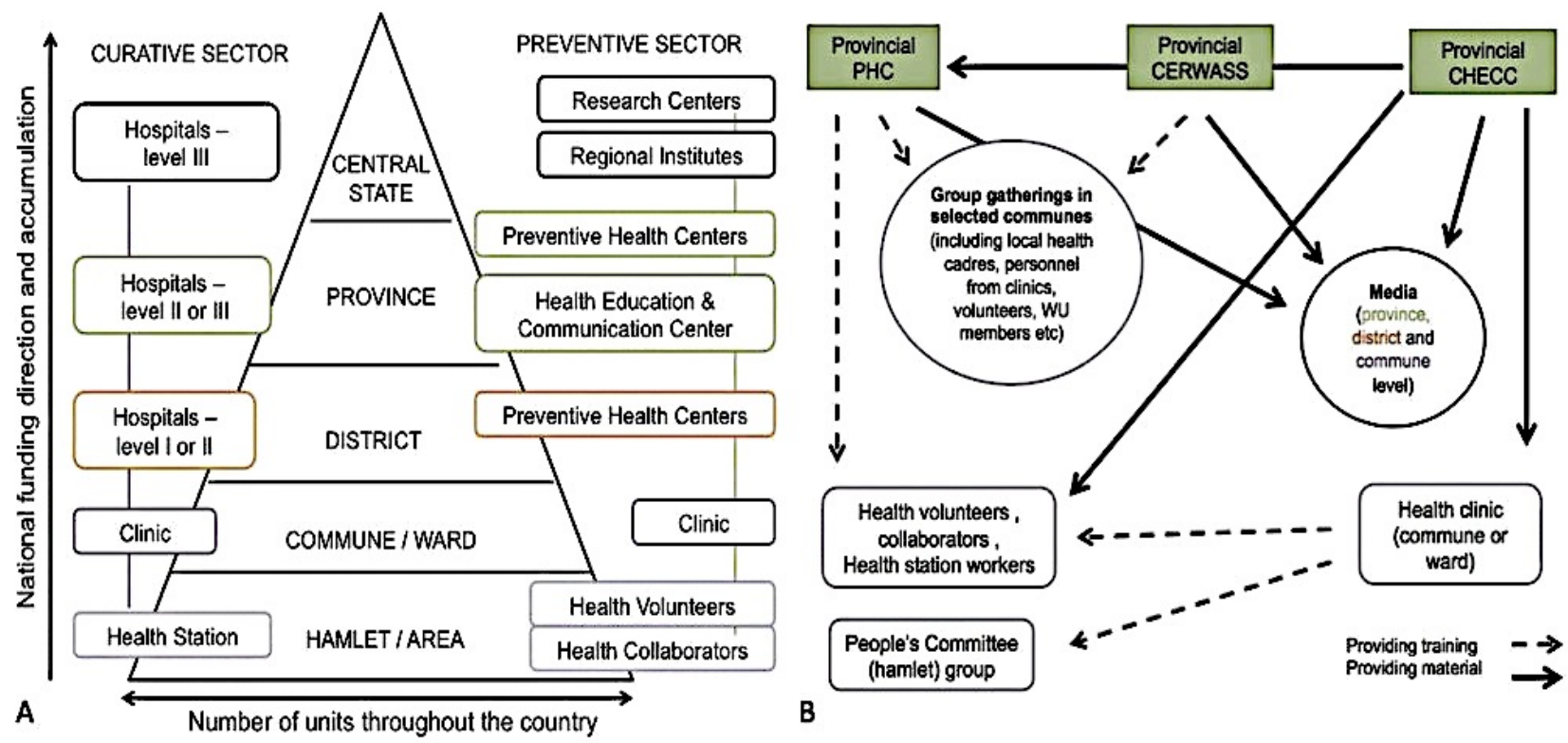

Figure 5: The hierarchical administrative division of healthcare and health prevention institutions in Vietnam. A. The hierarchy of health institutions in Vietnam. The position of each type of institution in the pyramid indicates the administration unit to which they belong. B. The direction of training events given and material related to health prevention. The number and frequency of both events and materials varies widely. Abbreviations: CERWASS $=$ Center for Rural Water Supply and Sanitation, CHECC= Can Tho Health Education and Communication Center. Sources: Based on semi-structured interviews with health authorities, as well as on legal documents and reports issued by the $\mathrm{MoH}(2006,2007)$.

Only party members, local health workers or Union members can become 'local communicators' and are thus prioritized as participants in training events. ${ }^{5}$ As a result, many of the poor and socially marginalized are excluded from these activities. But even though the responsibility of spreading health messages to the wider public falls entirely onto the local communicators, the latter work in a semi-voluntary basis (GoV 2010) and often quit after a few months of service (UNICEF 2011). Moreover, the position and role of the health communicator is not mentioned in any policy document produced by the MoH. The legal absence of these posts was justified by the claim that they only operate in a rather informal fashion and only in Southern Vietnam. ${ }^{6}$

Local communicators diffuse health messages through door-to-door visits. Interviewed household members described such visits as inspections rather than constructive dialogue. As informants further claimed, the prevention of diarrheal disease was rarely included as a topic:

Some people come here for the population survey, some others will come to check on whether we have mosquitoes in the house and show us how to avoid them [...] they do not mention anything about drinking and eating habits. The people from the clinic don't come, only the hamlet leader who is also running the local water supply station, to check if we are connected

\footnotetext{
${ }^{5}$ Semi-structured interview, health clinic worker in a rural commune, Phong Dien district.

${ }^{6}$ Semi-structured interview, representative of the HSPI.
} 
to the water scheme or if we have a hygienic toilet. (Resident in Phong Dien district and mother of one, in-depth interview)

Interviews revealed that the content of preventive health messages is not negotiated with the public, and the sharing of opinions is not fostered in these instances of door-to-door communication. High-level officers and experts discussed how IEC is far from achieving its objectives of participation in the region:

People [health communicators] at the local levels do not have the capacity or the education to understand everything that is involved in a health issue. Also, they do not care whether the population understands or not; they only care to tick the box of visiting the households and fill in their reports that they did it. (semi-structured interview, NGO water expert)

A content analysis of 16 collected documents used in IEC (brochures, radio broadcasts, posters and text provided in training events) from central, provincial and district level health authorities demonstrated that overall messages on diarrhea prevention miss key messages of prevention. The motto "eat cooked food and drink boiled water" appeared in $80 \%$ of the collected material, followed by the "wash hands after using the toilet/ before meals" (70\%) and "do not exercise open defecation" (60\%). However, other important aspects of hygiene, like hand-washing with soap (25\%), controlling the spread of flies (12.5\%) or keeping toilets functional, clean and environmentally sustainable (25\%), were downplayed. Analyzing IEC material from central versus local offices, and comparing this to discourse generated by the interviewed officials, it becomes clear that the content of health communication messages weakens as it travels to the level of the district, and below. The breadth of information provided at those levels is limited, with $80 \%$ of interviewees never mentioning globally-advocated measures of diarrhea prevention, like continued breast-feeding of infants, or Rotavirus vaccination. Overall, the discourse and the messages commonly used in localities fall short of explaining what can cause or prevent disease, and why.

The top-down character of formulating and communicating health messages in Vietnam (Figure 5) has been identified as the main reason why IEC has not managed to close the gap between information availability and peoples' practices, especially when it comes to disease prevention (Laverack and Dap 2003). One example of this is the approach taken towards Traditional Vietnamese Medicine (TVM), which although widely respected and commonly practiced in Vietnam (Ladinsky, Volk, and Robinson 1987; Wahlberg 2006), is absent from health education messages (MoH 2007). Household survey findings indicate that boiling water for drinking is the strategy for preventing diarrheal disease most frequently mentioned, while knowledge of other strategies is limited (Figure 6).

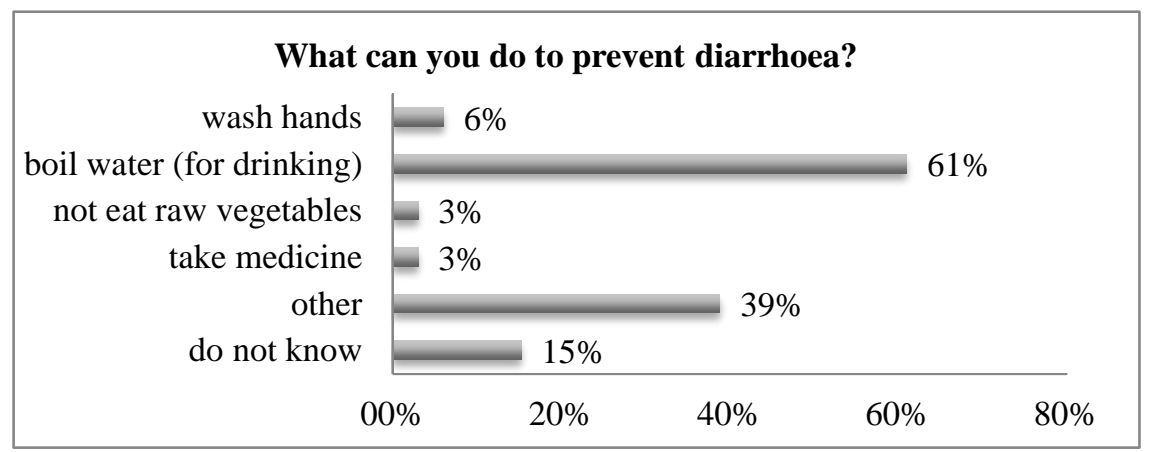

Figure 6: Distribution of answers regarding preventive measures against diarrheal disease Household survey (N=131), multiple-answer question. 2011. 
Some 39\% of the responses (grouped as 'other'), referred to the use of natural remedies linked to TVM (i.e. dark tea, coffee with lemon, aged mangosteen liquor, ginger tea, young green guava leaves). In another question, $15 \%$ explicitly said that in case of diarrheal disease they would first turn to TVM for treatment before following any other strategy. Looking at the process and the outcomes of health education, messages around diarrhea not only lose quality and impact as they travel to the local levels, they are also not attentive to feedback from their intended audience.

\section{Passing down public health responsibilities and individualizing disease}

A core stated objective in the National Health Strategy is to "change the awareness and raise the sense of responsibility for disease prevention and health protection in all of Party Committees [...], in mass organizations, in the community and every citizen" (MoH 2007: 81, my emphasis). Indeed, the bureaucratic system in Vietnam demands detailed reporting on the progress of each aspect of policy planning. Following this logic, public health responsibilities are quantified, compartmentalized and transferred to the localities. This allows for ambitious targets to be set centrally, defining for instance the percentage of wat/san access or of diarrhea case reduction to be achieved each year, country-wide (MARD 2010; MoH 2007). Such expectations are directly transferred to the lower levels of administration (Department of Health 2009; PHC Phong Dien 2011). However, very little support is directed to assist the everyday work of promoting public health messages and carrying out the implementation of wat/san programs, which is taken up mostly by districts and communes (Figure 5). In other words, it is the fault of district authorities if all households within their jurisdiction do not have improved access to water, as the government target of universal access to piped water demands.

In response, district and commune health authorities employ a discourse of responsibilization ${ }^{7}$ that $^{-1}$ trickles down to households and individuals:

The National sanitation and clean water week is organized as a response, to provide extensive propaganda to the masses and gradually raise the awareness of people, in order to improve their living conditions, to create healthy communities in rural areas and to contribute to a more modern and civilized society. This can be achieved if each of us in the social communities is aware of their hygiene practices. (PHC Binh Thuy 2011)

Concepts such as the 'healthy and cultural' neighborhood or village, and the 'healthy family' are included in official policy as measurable categories of social cohesion and local organization (MoH 2004). These titles are destined for those units that achieve - among other aspects - a certain health performance (e.g. a low number of food poisonings, children with malnutrition, smoking, alcohol consumption, and having hygienic latrines). The local scaling of health targets reproduces a vision of society as a collection of hierarchically associated, legible, measurable and thus governable units. This might be convenient for the way the Vietnamese state chooses to organize and exercise its hegemony, but largely misses the problems emergent in the complexity of the whole. Moreover, as this scaling down carries to the level of the family, it becomes charged with notions of responsibility for the individual or the community, presenting "free choices" as the source of health problems. The failure to address problems of diarrheal disease can be conveniently presented as a result of bad habits and undisciplined behaviors that need to be (self)regulated, rather than traced to state malfunction, bad policy or political unwillingness.

Even though misconceptions and malpractice regarding water hygiene and sanitation were documented in urban and rural, poor and better-off households, many portrayed hygienic misbehavior and the spread of disease as the inevitable fault of people living in poverty. On some occasions people's financial situation was acknowledged as a constraint to adopting healthier choices. However, the line between critical

\footnotetext{
7 'Responsibilization' means a process where people become responsible for a task which previously would have been the duty of the state, or of other individuals. Sometimes, the task did not exist previously and is new. It is a common phenomenon in neoliberal regimes, where individuals become responsible for the tasks of the welfare state.
} 
observation and prejudiced opinion was often blurred, particularly when presenting people living in poverty as unconcerned about their health:

Only few people follow the advice they get. They stick to their [unhygienic] habits, which are difficult to change, and sometimes their living conditions are unfavorable. For example, when they don't have clean water access, how are they going to protect themselves from unclean water? The very poor, in the deep rural areas, don't want to connect to the water supply system. When people are facing poverty, they don't seem to care about their health that much. (Representative of district PHC, urban area, semi-structured interview)

The poor are more likely to suffer from diseases [...] They know what to do, but they cannot afford it, or don't bother thinking about it; they don't have good living conditions nor good eating and drinking habits. (Representative of district PHC, rural area, semi-structured interview)

After a tiring day at work, the people cannot think to wash their hands. Each family has soap, but they won't use it before eating, because they only care about eating at that moment. Some people are in constant worry and struggle to survive, so health or hygiene is not in their priorities. (Representative of district PHC, rural area, semi-structured interview)

Normalizing poverty as the inevitable but unproblematized provenance of unhealthy choices or behaviors takes no account of factors that increase people's vulnerability to disease, such as state tolerance of industrial water pollution (Tan 2015; World Bank 2008), the inaccessibility of good quality public health care (Fritzen 2007; Kotsila 2012; London 2008), or the lack of accessible alternatives to obtain safe drinking water (Reis and Mollinga 2012). All of these are experienced in the Mekong Delta. A father of three, in Yen Binh area, describes the difficult position of being aware of health risks, but yet not finding ways to escape them:

Three years ago I could drink water from the river but now it is too dirty. In general, floating houses do not have a toilet. People realize they are causing the water to be dirty and the risks of getting diarrheal disease from this water, but there is no other choice for us. (Urban resident, personal communication)

As Reis (2012: 96) has argued, sustainable year-long access to clean water in the region is complicated, but it is primarily a question of financial capacity. This was indeed acknowledged by many of the interviewees in Can Tho:

Well, those who have money they buy bottled water, or a water purifier and their kids know that when they get thirsty they can drink this water. (Rural resident, personal communication)

Those who still cannot have access to water supply mini-stations will drill their own wells. The poor, who cannot afford this, will collect rainwater. (Representative of district PHC, semistructured interview).

Access inequalities are pronounced when comparing rural/urban households in the country (see Figure 3 and 4). In Can Tho City, almost all urban households are reported as having access to piped water, but only 39\% of the rural ones (Center for Rural Water Supply and Sanitation [CERWASS] 2011; PHC Ninh Kieu 2011). Similarly urban districts in Can Tho had 70 to $100 \%$ access to improved sanitation, but it was as low as $29 \%$ in rural ones (Ibid. 2011). There are a considerable number of people lacking access to piped water 
and/or improved sanitation within urban areas too (Kotsila and Saravanan, in press). Nonetheless, they constitute statistical minorities and, as such, they escape the scope of health education programs for diarrhea, because the latter are attached to the promotion of wat/san improvements in rural areas.

Although access to improved facilities proves to be a function of class and income level, findings revealed unhygienic and risky practices among poor and better-off households, as well as in many public facilities like schools and hospitals. Regarding household water treatment, although tap water is the only pretreated source, it is the main one that is additionally treated in the household (for a detailed account of the statistics, see: Kotsila 2014: 217). Water quality analysis from Can Tho and surrounding areas shows that the non-treatment of well- or rain-water poses increased risks of exposure to a range of pollutants, including the enterobacteria that cause diarrhea (Buschmann et al. 2008; Van Toan et al. 2013; Wilbers et al. 2013). But piped water schemes have greater health promotion about the risk of diarrhea, which could partially explain why more care is taken and well and rainwater largely goes untreated.

Considering sanitation, despite the high percentage of respondents saying they would prefer using a hygienic latrine than a fishpond toilet, ${ }^{8}$ in-depth interviews showed that the former is often (mis)understood as a "closed room, with a toilet bowl" and/or with a "strong water-flush". Many of those who reported having "hygienic" latrines, later described that their sewage is actually discharged straight into the river. Surface water pollution would not be associated with such practices, but with other people's fishpond toilets and "habit of throwing garbage in the river."

Confusion and contradictory practice demonstrates a widespread lack of systemic understandings around the water and sanitation matrix upon which diarrheal disease depends and spreads. Instead of acknowledging and addressing this gap, the IEC approach further compromises such understandings by focusing on narrow, didactic and individualized health messages. The content analysis of IEC material shows messages consisting of 'do's' and 'don'ts', mostly regarding water treatment and toilet types at household level (see previous section). Echoing policy that is geared to promote piped wat/san improvements, mostly through the uptake of micro-credit loans (CERWASS 2003 2010), health messages bring the problem of diarrhea down to the private/personal sphere; thereby detaching it from wider problems (i.e. sewage collection and treatment, holistic community health awareness, and poverty alleviation) and 'individualizing' it. This included food safety messages, such as: "do not eat fish and seafood, especially not raw" (in 40\% of the IEC material), "do not eat raw vegetables" (30\%) and "avoid eating out in mass servings like weddings or funerals" (20\%). These messages miss the root causes, and are going against central elements of everyday culture in Vietnam, contradicting governmental claims of promoting meaningful health practices that are "suitable for the target groups and their cultural and national traditions" (GoV 2007: 59).

\section{Moralizing disease: public health linked to socio-cultural identity}

As I have shown, the "cultural and healthy" policies define and measure certain (exemplary) behaviors, practices, and outcomes related to such attributes (MoH 2004). In Vietnam, 'culture' often refers to the pre-capitalist virtues of the countryside and the peasantry, promoted as enduring traditions in contemporary Vietnamese society (Popkin 1979). When official policy discourse links "mass organizations, the community and every citizen" (MoH 2007: 81) and "cultural" to "healthy" virtues, not only does it draw a relationship of interdependence between different socio-political units, but it also renders social conduct and individual bodies as subjected equally to moral judgment and/or Party appraisal. Coupled with the common portrayal of those vulnerable to disease as ignorant, dirty or indifferent towards state advice, this frames disease as an indicator of social misbehavior (against 'culture').

Such underlying moral notions in policy have been transferred to everyday people, finding expression in the blaming of others as the carriers of disease and as practitioners of unhygienic habits. Avoiding the stigma of being identified as someone suffering from disease is another outcome. When asked about the frequency of experiencing diarrhea, most respondents said they rarely ever get it and they wanted to change

\footnotetext{
${ }^{8}$ Fishpond toilets are open defecation constructions, typically over small fishponds, which consists of a small individual stall supported by bamboo canes.
} 
the subject, without elaborating further. After the researcher specified what "rarely" means, $70 \%$ proved to be suffering from diarrhea more than once a year. Notably, avoiding such conversations didn't indicate a feeling of aversion or disgust towards the disease and causation, but a particular hesitance or denial of talking about these things in relation to themselves or their families:

Getting diarrhea makes you feel weak, you can't go to work... Your belly hurts and your whole body hurts. You have to drink strong black tea and these pills help in making it stop. [PK: But, you said no one in this family ever gets diarrhea, how come you have these pills?]. I have them in case my neighbor needs them [...] One time a friend of mine had diarrhea and couldn't dare to wear pants because he had to run to the toilet every so often [laughs], so he had a towel wrapped around him for 4 days. (Rural resident, household survey interview P13)

Resonating with public health discourse, many - although not all - respondents would assign diarrhea to the poor residents of rural areas "who are not careful on how they feed their babies", or "drink raw water" (Household interview P42); generally assuming that people other than themselves performed risky practices that lead to illness. This was further visible in strict perceptual divisions between the safety of 'inside' and 'outside'. 'Dirty' or 'improper food was identified as the main cause of diarrhea (74.8\%), but respondents specified school canteens, street-vendors or restaurants as sources, and not their own kitchens. When asked directly whether water can cause disease, most replied negatively (76.3\%), thinking that the question was referring to water consumed in their household. After clarifying the generic scope of the question, respondents spoke about "disgusting water in the river", "dirty water out there that can cause cholera" and "water that people don't boil and can make you sick" [my emphasis]. Answers were accompanied with hand movements or body motions (i.e. looking outside, pointing at the door or the street) to signify and emphasize the distance between disease-causing factors and one's own living environment.

Notably, only seven out of 131 survey respondents were willing to speak openly about the frequency of their experience with diarrhea. All of the latter were low-income elderly individuals who were living on their own, the majority men. Women respondents with young kids, on the contrary, would get particularly uncomfortable with these questions, even avoiding articulating the word 'diarrhea.' The moral attributions that are discursively ascribed to diarrheal disease, bringing public health responsibilities down to the private/individual level and at the same time linking cultural compliance to health profiles, suggest this was not joust 'positive bias' in attributing risk (Frewer, Shepherd, and Sparks 1994).

Health understandings and practices become social behaviors related to the hierarchical balances between individual, family and society, which as Gammeltoft notes, are preserved in Confucianism - the "intellectual and ideological backbone of Vietnam" (Gammeltoft 1999: 134). The re-focus on the unit of the family since agricultural de-collectivization implied a shift in cultural norms that would "assign women the responsibility of safeguarding a family's well-being" (Waibel and Glück 2013), and emphasize their prescribed role to "encourage household harmony by adjusting themselves and, in so doing, make social life smooth" (Rydstrøm 2003: 676). From this vantage point, charging the household with public health responsibilities and expectations places mother/wife identities under a biopolitical moral gaze, and could explain why particularly women pronounced and protected a "healthy" reputation for themselves and their families.

\section{Discussion and concluding remarks}

The findings and analysis in this article contribute to a more nuanced understanding of diarrheal disease as a socio-political and cultural phenomenon, turning attention to the circulating discourses and onthe-ground practices related to diarrheal disease. I find that the discourse that guides and penetrates communication efforts around the prevention of diarrhea carries notions of disease individualization, stigmatization and moralization. Examining such discursive notions along with the local (mis)perceptions and (risky) behaviors around water, sanitation and diarrhea, the latter emerge as the result of a number of 
associated structural constraints. These include not only a lack of economic resources for poorer households, but also the lack of access to useful and empowering health information, and the cultivation of stigma, guilt and shame around disease. As explained, such forms of health dispossessions are exerted because they serve the political purpose of taking public health responsibilities away from policy-makers, assigning failures to particular social groups and identities, and ultimately maintaining the state's legitimacy as a good implementer and a "caring head." One of the questions for future research that emanate from, but are not addressed in, this article concerns the extent to which such discourse actually manages to convince Vietnamese citizens, civil society and local implementers; in other words, are there potential forms of resistance that respond to these health dispossessions and ways that such (self)governance mechanisms are being counteracted?

\section{Policies and politics of health dispossessions}

Legal planning documents indicate a high level of dedication in public health from the side of the Vietnamese state, at least on paper (MoH 2007, 2010). The analysis of its implementation, however, shows that uptake and impact are compromised. Overall, the health education system is lacking in content, methods and means. National targets are downscaled to the localities but financial support is denied to the grassroots institutions accountable for the promotion of preventive measures. For diarrhea specifically, health messages are attached to rural projects that promote wat/san construction. This disregards other aspects of diarrhea prevention (e.g. Rotavirus vaccination, breast-feeding) and behavioral "software" aspects around water and sanitation (i.e. toilet maintenance, hand-washing with soap), thus weakening the potential of such constrictions for health gains (Cairncross et al. 2010). Moreover, a unique focus on rural areas turns a blind eye to the urban poor, who face the same public health risks as their rural counterparts.

The submerging of diarrhea prevention under the promotion of wat/san speaks of the tendency in western-inspired development policy to translate life (and health) through indicators (Molle and Mollinga 2003; Schmidt 2014) and to use blueprint solutions that focus on the 'hardware' (technologies, materials and facilities). Whereas access to clean water and safe sanitation is pivotal for human health, such approaches tend to leave behind aspects of local culture and politics. In consonance with the above, I do not advocate for an abandonment of the 'hardware' in public health, but for a just distribution of more bottom-up inspired solutions, coupled with 'software' measures that can involve and empower communities in all aspects of disease prevention.

Policy planning in Vietnam has been criticized as constituting a façade that serves the state and its powerful bureaucracies (Benedikter 2014; Fforde 2011; Gillespie 2001). Reis and Mollinga (2012) explain how the Vietnamese wat/san sector is a hybridized private/public economy in which high-level officers are involved in businesses that take charge of public works. A reported wide expansion of wat/san facilities puts Vietnam in a good light for international development donors (Reis 2016) and thus facilitates the flow of capital. While it is not within the scope of this article to delve into the conflictive interests of the wat/san development sector, I show that paying attention only to 'hardware' goals and indicators sidetracks from what is experienced and needed on the ground. Despite TVM being a vivid part of contemporary medical practice, for example, and even praised as part of national identity and a symbol of the revolutionary ethos against colonial rule (Marr 1992; Wahlberg 2006), it is absent from any official public health or disease prevention program.

The Vietnamese state not only wishes to portray itself externally as a 'good implementer', it also wants to ensure a central domination over discourse that surrounds issues of public health internally. It does so, on the one hand, by maintaining a centralist approach in public health education, where instructions 'trickle down' to local institutions, while participation and feedback from citizens and communities is not fostered in any meaningful way. A 'Confucian' hierarchy, still evident in state-society interfaces in Vietnam, can explain this tendency for top-down control to some extent (Kerkvliet 2001; Nghia 2005). Seen in the context of health, this further resonates with a Foucauldian interpretation of biopolitics, the state being the "interpreter 
of life" and every individual being equally unequal in having a say on such vital matter; the public ("body") is thereby treated as needing guidance from the knowledgeable and caring Party-state ("head") (as cited in Prozorov 2007: 118). Despite establishing its powerful role, however, the state does not fulfill the biopolitical objectives that it sets. Findings show that diarrhea persists, access to wat/san remains problematic and prescribed behaviors are often not followed. As I describe below, another way in which the state maintains its hegemonic position is by eliminating the space for criticism of the failed outcomes of its policies, portraying such failures as a matter of peoples' individual choices and behaviors.

\section{Discourses of blame as tools of governance}

Health messages were found to shift attention to the private sphere and thus to boil diarrhea prevention down to the responsibility of households and individuals. This takes the blame away from systemic biophysical or social factors that allow the spread of disease, and instead places it on those who 'allow' the spread of disease to affect them. Instead of being recognized as agents of health prevention in need of the right tools, people are portrayed as factors of risk associated with diarrhea (individuals who are making the 'wrong choices', the poor who don't care about their health). This comes in conjunction with a discursive blending of social values with bodily experiences, and of health-related behaviors with cultural compliance. As seen in the example of the 'cultural and healthy' policy, where hygienic behaviors, social conduct and cultural values are glued together, disease is being morally charged. A closer analysis of the interviewees' documented reactions showed why this moralization can cause feelings of guilt and shame, turning diarrheal disease vulnerability into a signifier of failure in fulfilling prescribed social roles. Ultimately, this is forging the pronouncement of successful compliances with public health rules and expectations, even when in effect people remain exposed to diarrheal disease.

The case of Vietnam reveals a type of neoliberal health individualization and responsibilization that not only claims that the ill are responsible for burdening the public health system due to their bad health choices or lifestyles, but also implicitly depicts them as second-rate partisans/citizens/family members. This responsibilization thus functions in the moral-ideological domain and acts as a tool of governance, based on health-related "technologies of self", through which "aspects of self-constitution are carried out rendering particular images, statuses and identities into being" (Ayo 2012). As Lincoln (2014) has previously noted, Self/Other oppositions that do not necessarily comply with epidemiological facts, serve to shift attention from a suffering water and sanitation sector in Vietnam. Similarly, IEC for the prevention of diarrheal disease lacks the characteristics that would allow community health empowerment - a dialectical process of individual and social change which is health enhancing, challenges dominant prevention paradigms and welcomes alternative, traditional, herbal or other ways of understanding and treating disease (Labonté 1993; Wallerstein and Bernstein 1994). In conclusion, instead of aiming to promote empowerment, the discourse of diarrhea that circulates in this case aims to conceal a number of discrepancies, injustices and dispossessions in public health, and thus to contribute to the legitimization of state approaches and policies.

\section{References}

Aunger, R., W.P. Schmidt, A. Ranpura, Y. Coombes, M. Maina, C.N. Matiko and V. Curtis. 2010. Three kinds of psychological determinants for hand-washing behaviour in Kenya. Social Science and Medicine 70(3): 383-391.

Ayo N. 2012. Understanding health promotion in a neoliberal climate and the making of health conscious citizens. Critical Public Health 22(1): 99-105.

Baer, H.A. 1996. Toward a political ecology of health in medical anthropology. Medical Anthropology Quarterly 10(4): 451-454.

Benedikter, S. 2014. the Vietnamese hydrocracy and the Mekong Delta: water resources development from state socialism to bureaucratic capitalism. Münster: LIT Verlag. 
Blaikie, N. 2009. Designing social research. Cambridge: Polity Press.

Bloom, G. 1998. Primary health care meets the market in China and Vietnam. Health Policy 44: $233-252$.

Bohle, D. and B. Greskovits. 2007. Neoliberalism, embedded neoliberalism and neocorporatism: towards transnational capitalism in Central-Eastern Europe. West European Politics 30(3): 443-466.

Brown, P. and S. Zavestoski. 2004. Social movements in health: an introduction. Sociology of Health and Illness 26(6): 679-694.

Brown, T. and Duncan C. 2002. Placing geographies of public health. Area 34(4): 361-369.

Bui, H.T. 2015. In search of a post-socialist mode of governmentality: the double movement of accommodating and resisting neo-liberalism in Vietnam. Asian Journal of Social Science 43(1-2): 80102.

Bullard, R.D., and J. Lewis. 1996. Environmental justice and communities of color. San Francisco, CA: Sierra Club Books.

Buschmann, J., M. Berg, C. Stengel, L. Winkel, M.L. Sampson, T.K. Trang and H. Viet. 2008. Contamination of drinking water resources in the Mekong delta floodplains: Arsenic and other trace metals pose serious health risks to population. Environment International 34(6): 756-764.

Cairncross, S., J. Bartram, O. Cumming and C. Brocklehurst. 2010. Hygiene, sanitation, and water: what needs to be done? PLoS Medicine 7(11): e1000365.

Cavill, S., S. Cairncross, J. Brown, R. Rheingans, J. Mulligan, H. O'Connor, W.P. Schmidt, J. Ensink, S. Baker, M. Harvey, O. Cumming, A. Jeandron, L. Ryan-Collins, J. Amery, S. Bibby, G. Howard, P. Swann, S. Wijesekera and D. Woolnough. 2013. Water, sanitation and hygiene: evidence paper. London: Department for International Development.

CERWASS. 2003. Guidelines on information-education-communication (IEC) for rural water supply and environmental sanitation. Hanoi: Ministry for Agriculture and Rural Development (MARD).

CERWASS. 2010. Collecting data on water supply and sanitation for households in Can Tho, by commune. Can Tho: CERWASS.

CERWASS. 2011. Collecting data on water supply and sanitation for households in Can Tho, by commune. Can Tho: CERWASS.

Couacaud, L. 2014. Hookworm disease and its relationship to capitalism and urban development. Journal of Political Ecology 21: 349-371.

Curtis, V., S. Cairncross and R. Yonli. 2000. Review: domestic hygiene and diarrhoea - pinpointing the problem. Tropical Medicine and International Health 5(1): 22-32.

Department of Health. 2009. Report on health and plans I and II for 2009. Can Tho City: Department of Health.

Douglas, M. 1970 (1966). Purity and danger: an analysis of concepts of pollution and taboo. London: Routledge.

Ehlert, J. 2011. Living with flood: local knowledge in the Mekong Delta, Vietnam. Münster: LIT Verlag.

Escobar, A. 1997. The making and unmaking of the third world through development. In Rahnema, M. and V. Bawtree (eds.) The post-development reader. University of Chicago Press. Pp. 85-93.

Feierman, S., A. Kleinman, K. Stewart, P. Farmer and V. Das. 2010. Anthropology, knowledge-flows and global health. Global Public Health 5(2): 122-128. Researchgate

Fforde, A. 2011. Contemporary Vietnam: political opportunities, conservative formal politics, and patterns of radical change. Asian Politics and Policy 3(2):165-184.

Forsberg, L.T. .2011. The political economy of health reform in Vietnam. Working paper 2011. OxfordPrinceton Global Leaders Program. Oxford University.

Foucault, M. 1991. Governmentality. In G. Burchell, C. Gordon, and P. Miller (eds.). The Foucault effect: studies in governmentality. University of Chicago Press. Pp. 87-104. 
Foucault, M., G. Burchell, C. Gordon and P. Miller (eds.). 1991. The Foucault effect: studies in governmentality. University of Chicago Press.

Frewer, L.J., R. Shepherd, and P. Sparks. 1994. The interrelationship between perceived knowledge, control and risk associated with a range of food-related hazards targeted at the individual, other people and society. Journal of Food Safety 14(1): 19-40.

Fritzen, S.A. 2007. Legacies of primary health care in an age of health sector reform: Vietnam's commune clinics in transition. Social Science and Medicine 64(8): 1611-1623.

Gainsborough, M. 2010. Present but not powerful: neoliberalism, the state, and development in Vietnam. Globalizations 7(4): 475-488.

Gammeltoft, T. 1999. Women's bodies women's worries: health and family planning in a Vietnamese rural community. London: Curzon Press.

Geddes, M. 2000. Tackling social exclusion in the European Union? The limits to the new orthodoxy of local partnership. International Journal of Urban and Regional Research 24(4): 782-800.

Gillespie, J. 2001. Self-interest and ideology: bureaucratic corruption in Vietnam. The Australian Journal of Asian Law 3(1): 1-36.

Goldberg, D.S. 2012. Against the very idea of the politicization of public health policy. American Journal of Public Health 102(1): 44-49.

GoV. 2006. National target program for rural water supply and sanitation (2006 - 2010). Final Draft. Hanoi. Government of Vietnam.

GoV. 2007. On the prevention and control of infectious diseases. 03/2007/QH12. Hanoi: Government of Vietnam.

GoV. 2010. On the declaration, information and reporting of infective diseases. 48/2010/TT-BYT. Hanoi: Government of Vietnam.

GSO. 2013. Statistical handbook 2012. Hanoi: General Statistics Office of Vietnam.

Guttman, N. and C.T. Salmon. 2004. Guilt, fear, stigma and knowledge gaps: ethical issues in public health communication interventions. Bioethics 18(6): 531-552.

Heller, L., E.A. Colosimo and C.M.F. Antunes. 2003. Environmental sanitation conditions and health impact: a case-control study. Revista Da Sociedade Brasileira de Medicina Tropical 36(1): 41-50.

Herbst, S., S. Benedikter, U. Koester, N. Phan, C. Berger, A. Rechenburg and T. Kistemann. 2009. Perceptions of water, sanitation and health: a case study from the Mekong Delta, Vietnam. Water Science and Technology 60(3): 699-707.

Hunt, A. 2003. Risk and moralization in everyday life. In R.V. Ericson and A. Doyle (eds.) Risk and morality. Toronto: University of Toronto Press. Pp. 65-192.

Institute of Health Metrics and Evaluation [IHME]. 2010. Global burden of diseases, injuries, and risk factors study. Seattle: Institute of Health Metrics and Evaluation.

Jackson P. and A.H. Neely. 2015. Triangulating health: toward a practice of a political ecology of health. Progress in Human Geography 39(1): 47-64.

Janes, C.R., O. Chuluundorj, C.E. Hilliard, K. Rak and K. Janchiv. 2006. Poor medicine for poor people? Assessing the impact of neoliberal reform on health care equity in a post-socialist context. Global Public Health 1(1): 5-30.

Jensen K., J.H. Ensink, G. Jayasinghe, W. Van Der Hoek, S. Cairncross and A. Dalsgaard. 2002. Domestic transmission routes of pathogens: the problem of in-house contamination of drinking water during storage in developing countries. Tropical Medicine and International Health 7(7): 604-609.

JMP Vietnam. 2012a. Estimates for the use of improved drinking-water sources. Joint Monitoring Program (JMP) of the WHO and UNICEF. JMP Vietnam. 
JMP Vietnam. 2012b. Estimates for the use of improved sanitation facilities. Joint Monitoring Program (JMP) of the WHO and UNICEF. JMP Vietnam.

Joshi, D., B. Fawcett and F. Mannan. 2011. Health, hygiene and appropriate sanitation: experiences and perceptions of the urban poor. Environment and Urbanization 23(1): 91-111.

Kerkvliet, B.J.T. 2001. An approach for analysing state-society relations in Vietnam. Sojourn: Journal of Social Issues in Southeast Asia 16(2): 238-278.

Kinchy, A.J. 2010. Anti-genetic engineering activism and scientized politics in the case of "contaminated" Mexican maize. Agriculture and Human Values 27(4): 505-517.

Köster, U. 2008. Gesundheit, wasser und hygiene. Eine fallstudie aus dem Mekong Delta, Vietnam. Institute of Regional Sciences Southeast Asia. Bonn: Rheinische Friedrich-Wilhelms-Universität. (Health, water and hygiene. A case study from the Mekong Delta, Vietnam)

Kotsila, P. 2012. "Health is gold": institutional structures and the realities of health access in the Mekong Delta, Vietnam. Working Paper Series 105. Bonn: Center for Development Research (ZEF), University of Bonn.

Kotsila, P. 2014. Socio-political and cultural determinants of diarrheal disease in the Mekong Delta: from discourse to incidence. Münster: LIT Verlag.

Kotsila P. and V.S. Saravanan. (in press). Biopolitics gone to shit? State narratives versus everyday realities of water and sanitation in the Mekong Delta. World Development.

Kuenzer, C., H. Guo, J. Huth, P. Leinenkugel, X. Li and S. Dech. 2013. Flood mapping and flood dynamics of the Mekong Delta: ENVISAT-ASAR-WSM based time series analyses. Remote Sensing 52: 687715.

Ladinsky, J.L., N.D. Volk and M. Robinson. 1987. The influence of traditional medicine in shaping medical care practices in Vietnam today. Social Science and Medicine 25(10): 1105-1110.

Langford, R. and C. Panter-Brick. 2013. A health equity critique of social marketing: where interventions have impact but insufficient reach. Social Science and Medicine 83: 133-141.

Laverack, G. and D.H. Dap. 2003. Transforming information, education and communication in Vietnam. Health Education 103(6): 363-369.

Lincoln, M.L. 2014. Tainted commons public health: the politico-moral significance of cholera in Vietnam. Medical Anthropology Quarterly 28(3): 342-361.

London, J. 2008. Reasserting the state in Viet Nam: health care and the logics of market-Leninism. Policy and Society 27(2): 115-128.

Lupton D. 1993. Risk as moral danger: the social and political functions of risk discourse in public health. International Journal of Health Services 23(3): 425-435.

Marr, D.G. 1992. Vietnam. World Bibliographical Series, Vol. 147. Oxford University Press.

MARD. 2010. Rural water supply and sanitation strategy up to year 2020. Hanoi: Ministry of Agriculture and Rural Development.

Mintz, E., J. Bartram, P. Lochery, and M. Wegelin. 2001. Not just a drop in the bucket: expanding access to point-of-use water treatment systems. American Journal of Public Health 91(10): 1565-1570.

$\mathrm{MoH}$. 2004. On promulgating the regulation on the title of healthy family, healthy neighborhood and healthy village or area certificate. 1635/2004/QD-BYT. Hanoi: Government of Vietnam.

MoH. 2006. Health metrics network: Vietnam health information system review and assessment. Hanoi: Ministry of Health, Government of Vietnam.

MoH. 2007. Vietnam national strategy on preventive medicine to 2010 and orientations towards 2020, and Master plan on development of Vietnam's health care system up to 2010 with a vision to 2020. Hanoi: Ministry of Health, Government of Vietnam. 
MoH. 2010. Five-year health sector development plan: 2011 - 2015. Hanoi: Ministry of Health, Government of Vietnam.

MoH. 2012. National health statistics on infectious diseases 2001-2010. Hanoi: Ministry of Health, Government of Vietnam.

Molle, F. and P. Mollinga. 2003. Water poverty indicators: conceptual problems and policy issues. Water Policy 5(5): 529-544.

Morello-Frosch, R., M. Pastor and J. Sadd. 2001. Environmental justice and Southern California's "riskscape": the distribution of air toxics exposures and health risks among diverse communities. Urban Affairs Review 36(4): 551-578.

Nash, L.L. 2006. Inescapable ecologies: a history of environment, disease, and knowledge. Berkeley: University of California Press.

Nghia, D. 2005. Confucianism and the conception of law in Vietnam. In Gillespie J. and P. Nicholson (eds.). Asian socialism and legal change: the dynamics of Vietnamese and Chinese reform. Canberra: ANU E Press. Pp.76-90.

Nichter, M. 1996. Health social science research on the study of diarrheal disease: a focus on dysentery. In M. Nichter and M. Nichter (eds.). Anthropology and international health: South Asian case studies. London: Routledge. Pp.111-134.

Nichter, M., and M. Nichter. 1996. Education by appropriate analogy. In M. Nichter and M. Nichter (eds.) Anthropology and international health: South Asian case studies. Routledge. (reprinted from 1986/1989)

Panter-Brick C., S.E. Clarke, H. Lomas, M. Pinder and S.W. Lindsay. 2006. Culturally compelling strategies for behaviour change: a social ecology model and case study in malaria prevention. Social Science and Medicine 62(11): 2810-2825.

PHC Phong Dien. 2011. Summary of the preventive health activities for 2009 and 2010. Vietnam: Can Tho.

Priwitzer, K. 2012. The Vietnamese health care system in change: a policy network analysis of a Southeast Asian welfare regime. Singapore: Institute of Southeast Asian Studies.

Prozorov, S. 2007. Foucault, freedom and sovereignty. Aldeshot: Ashgate.

Quesada, J., Hart, L. K., and Bourgois: 2011. Structural vulnerability and health: Latino migrant laborers in the United States. Medical Anthropology 30(4): 339-362.

Reis, N. 2012. Tracing and making the state: policy practices and domestic water supply in the Mekong Delta. Münster: LIT Verlag.

Reis, N. 2016. Good governance as managerialism: rationalisation and international donors in Vietnam's rural water supply and sanitation sector. Development Policy Review 34(1): 29-54.

Reis, N. and P. Mollinga. 2012. Water supply or "beautiful latrines"? Microcredit for rural water supply and sanitation in the Mekong Delta, Vietnam. ASEAS - Austrian Journal of South-East Asian Studies 5(1): $10-29$.

Rheinländer, T., H. Samuelsen, A. Dalsgaard and F. Konradsen, 2010. Hygiene and sanitation among ethnic minorities in Northern Vietnam: does government promotion match community priorities? Social Science and Medicine 71(5): 994-1001.

Richmond, C., S.J. Elliott, R. Matthews, and B. Elliott. 2005. The political ecology of health: perceptions of environment, economy, health and well-being among Namgis First Nation. Health \& Place 11(4): 349-365.

Rozin, P. 1999. The process of moralization. Psychological Science 10(3): 218-221.

Rydstrøm, H. 2003. Encountering "hot" anger domestic violence in contemporary Vietnam. Violence Against Women 9(6): 676-697. 
Schmidt, W. 2014. The elusive effect of water and sanitation on the global burden of disease. Tropical Medicine and International Health 19(5): 522-527.

Schwenkel, C. and A.M. Leshkowich. 2012. Guest editors' introduction: how is neoliberalism good to think Vietnam? How is Vietnam good to think neoliberalism? Positions 20(2): 379-401.

Singer, M. 2009. Introduction to syndemics: a critical systems approach to public and community health. San Francisco: Jossey-Bass.

Singer, M., F. Valentin, H.A. Baer and Z. Jia. 1992. Why does Juan Garcia have a drinking problem? The perspective of critical medical anthropology. Medical Anthropology 14(1): 77-108.

Smith, G.D., A. Gorter, J. Hoppenbrouwer, A. Sweep, R.M. Perez, C. Gonzales and P. Sandiford. 1993. The cultural construction of childhood diarrhoea in rural Nicaragua: relevance for epidemiology and health promotion. Social Science and Medicine 36(12): 1613-1624.

Springer, S. 2010. Neoliberal discursive formations: on the contours of subjectivation, good governance, and symbolic violence in posttransitional Cambodia. Environment and Planning D: Society and Space 28(5): 931-950.

Tan, S. 2015. Wastewater management in industrial zones of the Vietnamese Mekong Delta. A socio-spatial analysis of environmental management in a transition economy. $\mathrm{PhD}$ dissertation. University of Bonn.

Tesh S.N. 1988. Hidden arguments: political ideology and disease prevention policy. Rutgers University Press.

Thanh, V.T. and N.A. Duong. 2009. Vietnam after two years of WTO accession: what lessons can be learnt? ASEAN Economic Bulletin 26(1): 115-135.

Trach, D.D., J.D. Clemens, N.T. Ke, H.T. Thuy, N.D Son, D. Canh, P.V.D. Hang and M.R. Rao. 1997. The Lancet 349(9047): 231-235.

UNICEF. 2011. An analysis of the situation of children and WASH sector in Vietnam. New York: United Nations Children's Fund.

UNICEF. 2012. Pneumonia and diarrhoea: tackling the deadliest diseases for the world's poorest children. New York: United Nations Children's Fund.

UNICEF (Viet Nam). 2012. Two diseases remain biggest killers of East Asia-Pacific and Viet Nam children. Hanoi: UNICEF.

Van Man, N., L.T. Luan, D.D. Trach, N.T.H. Thanh, V. Tu, N.T. Long, D.D. Anh, T.K. Fischer, B Ivanhoff and J.R. Gentsch. 2005. Epidemiological profile and burden of rotavirus diarrhea in Vietnam: 5 years of sentinel hospital surveillance 1998-2003. Journal of Infectious Diseases 192 (Supplement 1), S127-S132.

Van Toan, P., Z.Sebesvari, M. Bläsing, I. Rosendahl and F.G. Renaud. 2013. Pesticide management and their residues in sediments and surface and drinking water in the Mekong Delta, Vietnam. Science of the Total Environment 452-453:28-39.

Wahlberg, A. 2006. Bio-politics and the promotion of traditional herbal medicine in Vietnam. Health 10(2): 123-147.

Waibel, G. and J. Ehlert. 2012. Fuzzy reality: social science research in Vietnam. $D+C$, Social Studies 53(5): 203-205.

Waibel, G. and S. Glück. 2013. More than 13 million: mass mobilisation and gender politics in the Vietnam Women's Union. Gender and Development 21: 343-361.

Wallerstein, N. 2006. What is the evidence on effectiveness of empowerment to improve health? Geneva: World Health Oranization.

WHO. 1987. Communication: a guide for managers of national diarrhoeal disease control programmes. planning, management and appraisal of communication activities. Geneva: World Health Organisation. 
WHO. 2001. Information education and communication: lessons from the past; perspectives for the future. Geneva: World Health Organization, Department of Reproductive Health and Research.

WHO. 2011. Country Health information profiles: Viet Nam. Geneva: World Health Organisation.

Wilbers, G.-J., Z. Sebesvari, A. Rechenburg and F.G.Renaud. 2013. Effects of local and spatial conditions on the quality of harvested rainwater in the Mekong Delta, Vietnam. Environmental Pollution 182(0) 225-232.

Witter, S. 1996. "Doi Moi" and health: the effect of economic reforms on the health system in Vietnam. The International Journal of Health Planning and Management 11(2): 159-172.

World Bank. 2008. Review and analysis of the pollution impacts from Vietnamese manufacturing sectors. Washington DC: The World Bank.

World Bank. 2013. Vietnam: achieving success as a middle-income country. Washington DC: The World Bank. 